\title{
Crane Lifting Optimization and Construction Monitoring in Steel Bridge Construction Project Based on BIM and UAV
}

\author{
Jiahao Tian $\mathbb{D}$, ${ }^{1}$ Sang Luo $\mathbb{D}^{2},{ }^{2}$ Xinming Wang $\mathbb{D}^{3},{ }^{3}$ Jing $\mathrm{Hu}\left(\mathbb{D},{ }^{2}\right.$ and Jun Yin $\mathbb{D}^{1}$ \\ ${ }^{1}$ School of Transportation, Southeast University, Nanjing 210096, China \\ ${ }^{2}$ Intelligent Transportation Research Center, Southeast University, Nanjing 210096, China \\ ${ }^{3}$ Transportation Bureau of Suzhou, Suzhou 215007, China \\ Correspondence should be addressed to Sang Luo; 101011363@seu.edu.cn
}

Received 3 March 2021; Revised 22 June 2021; Accepted 13 July 2021; Published 31 July 2021

Academic Editor: Ozgur Baskan

Copyright ( $\odot 2021$ Jiahao Tian et al. This is an open access article distributed under the Creative Commons Attribution License, which permits unrestricted use, distribution, and reproduction in any medium, provided the original work is properly cited.

Modular construction methods are adopted in many spatial and temporal limited projects. As the major equipment used in modular construction, the mobile crane affects the safety and efficiency of construction significantly. Currently, building information modeling (BIM) is widely adopted to improve the lifting operation planning of cranes. However, the inaccurate simulation of the dynamic construction environment makes those BIM-based lifting operation planning methods unsuitable for land mobile cranes operation planning, such as in the overpass bridge construction project, which may cause several safety risks during the lifting process. Based on an overpass steel bridge construction project, this paper attempted to integrate the BIM and unmanned aerial vehicles (UAVs) to streamline lifting operation planning and construction monitoring. Specifically, in the preliminary stage, a level of development (LOD) 400 steel superstructure model was built and then divided into eighty sections. In addition, a three-dimensional (3D) geology model of the as-is construction site was modeled by UAV-captured images. Then, a fusion model which contains the lifting modules models, the as-is site model, and the crane model was gathered, based on which the collision detection was conducted by $4 \mathrm{D}$ crane operating path simulation. According to the results, three potential collisions were found and eliminated by lengthening the jib of the crane from $43.5 \mathrm{~m}$ to $46.5 \mathrm{~m}$. Furthermore, the optimum crane location for lifting each steel structure was determined based on the 3D geology model. The study shows that the UAV is able to acquire geological information and then 3D simulates the real construction environment quickly and accurately. Furthermore, BIM and UAV have the potential to optimize the design and construction as well as the monitoring of bridge projects.

\section{Introduction}

According to Amap and State Information Center of China, in 2019 , there were $4 \%$ of cities in China with an urban traffic congestion delay index of more than 1.8 and $61 \%$ of cities with a peak congestion delay index of more than 1.5 , which means that the travel time under congested traffic situation was 1.5 or 1.8 times of the normal travel time without traffic congestion [1]. As one of the road structures, the crossbridge is built without intersections, which can free the vehicles from the burden of traffic lights and the interference of vertical traffic flow. However, the construction site of the overpass bridge is often located in prosperous and commercial areas with heavy traffic. Thus, the construction of an overpass is often subjected to several restrictions, including temporal and spatial restrictions.

To tackle those construction restrictions, many modular construction methods are adopted. Among those, the incremental launching construction technology is prevailing in steel box girder overpass bridge construction [2]. This kind of construction method involves breaking down the entire steel box girder into modules, prefabricating modules off-site, and transporting modules to the construction site [2]. The modules, which are always large and heavy objects, are typically lifted by cranes and then installed on the designed positions. As one of the key construction machines and due to the operation complexity, the operation of cranes is closely related to construction safety. According to the 
statistics from the Ministry of Housing and Urban-Rural Development of the People's Republic of China, in 2019, 7 out of 23 significant safety accidents were related to crane lifting operations, which account for around 30\% [3]. Thus, crane operation has emerged as a critical factor in steel box girder overpass construction.

However, in practice, even for experienced engineers, the mobile crane lift planning within congested areas for a complex project is usually a burdensome process, if based on the limited information provided by computer-aided design (CAD). Because the information provided by CAD is $2 \mathrm{D}$ drawing, it differs from the real construction process, which also makes operators suffer from the separation between the design and construction phases [4]. To address this problem, building information modeling (BIM) was introduced to the crane operation plan. As a kind of visualization technology, BIM can provide interaction between the crane operation plan and the surrounding environment [5], which is effective in simulating the movement and operation of the mobile crane.

Apart from the traditional considerations taken into the crane operation planning, the inconstant characteristics of interactions between the crane and other construction objects also aggravate the complexity of the crane operation planning [6]. To assist the crane operation, many information technologies were implemented during crane operation, such as the Internet of Things (IoT) and radio frequency identification [7]. However, those onboard sensors mainly focus on the movement of modules and the crane but fail to inspect the changes in the construction site. Furthermore, although some cameras and Global Position System (GPS) were also adopted to visualize the surrounding of the project in real time, the distance information from the crane to the obstacle is hard to estimate for mobile crane operators [8]. Nowadays, advancements in unmanned aerial vehicle (UAV) technology make it possible to model a wide range of construction sites efficiently. Specifically, the UAV can collect visual data (e.g., images, time, and location) quickly for a large-scale construction site. Then, by data processing (e.g., dense captioning), the large amount of acquired data can be managed effectively, and then, the construction environment will be quickly simulated in a 3D model during the construction process [9]. After file type conversion, the crane model, modules model, and construction site model can be integrated into a $3 \mathrm{D}$ virtual space, which can provide a better crane operation plan-aided.

This study attempts to integrate the BIM and UAV in the modular construction of a steel bridge to provide an accurate way in crane path planning and construction monitoring. The BIM is utilized to generate the crane and building model and the images obtained by UAV are adopted to analyze the existing environmental information. Thus, by integrating the designed 3D model of BIM and the as-is environment model of UAV images, the crane path plan was $4 \mathrm{D}$ simulated and the designed lift operation could be monitored dynamically. Furthermore, the as-is model can also be used for project schedule inspection and management.

This study is organized as follows. Section 2 reviewed the related researches about BIM, UAV, and traditional crane path planning methods. Then, Section 3 introduced the general information of the steel bridge project briefly. Sections 4 and 5 presented the generation of the 3D steel bridge model and the acquisition of the construction site, respectively. On this basis, the crane operation and working path were determined and shown in Section 6. After that, Section 7 introduced the utilization of the $4 \mathrm{D}$ model and UAV in construction schedule monitoring. Finally, Sections 8 and 9 presented the practical implications and concluded this study in brief, respectively.

\section{Theoretical Background}

2.1. BIM and UAV Technologies. BIM is proposed as a digital information database that can collect, manage, analyze, and process construction-related information throughout the whole construction duration [5]. Compared with the traditional construction management system, the BIM is able to generate multidimensional $(n-\mathrm{D})$ and data-rich models and is generally accepted as the most promising technology to optimize the construction quality, cost-effectiveness, efficiency, and sustainability [10]. Specifically, BIM can be utilized as an effective and efficient management tool in different phases of a new or existing infrastructure with varying purposes, such as position determination, energy simulation, construction schedule fabrication, cost evaluation, visualization, equipment management, and design drawing revision [11]. In addition, with the increasing pursue of safety in architecture, engineering, and construction (AEC) industry, BIM was utilized by many scholars to conduct safety inspections [12].

Typically, to enhance the resolution of BIM and monitor the construction schedule, innovative technologies were proposed to couple with the BIM. The UAV is one of the innovative technologies used in AEC industry construction safety monitoring [11]. The UAV was originally adopted for military purposes [11]. However, with the development of technology, the UAV is prevailing in the AEC industry and other fields recently. Owing to the application of real-time monitoring science, the UAV is able to capture the real-time images or videos of a construction site [13, 14]. Consequently, based on this advantage, the UAV is widely used in site surveys, visual detection, construction monitoring, infrastructure measurement, and safety risk detection [15-18]. Compared to other monitoring technologies, the UAV possesses the advantages of good portability, great flight stability, simple operation, real-time response, low cost, and high resolution [11].

Currently, scholars attempt to integrate the BIM and UAV from two approaches according to the function of UAV [16]. Specifically, in approach 1, the UAV is typically utilized to capture the geometric information of the construction site; on this basis, the BIM is generated and the potential hazard locations or steps can be inspected [19]. By contrast, in approach 2, the BIM is built before the utilization of UAVs. Based on the built BIM, the potential hazard is detected and then the UAV is adopted to conduct the safety check [20]. 
2.2. Automation in Crane Operation Planning. In prefabricated projects, mobile cranes are used for module lifting due to their excellent transportation capacity. Several studies have been conducted, such as path planning studies, crane system control strategy studies, operator situation awareness studies, as-is site condition information gathering, and mobile assets tracking studies [21-25]. Among those studies, lift path planning is a research hotspot because the lift path is a critical factor for both project safety and productivity, especially on a site with a limited area [26]. Two basic works are involved in lift path planning: environment information gathering and path determining.

\subsubsection{Construction Field Capturing Technologies.} Nowadays, to capture and monitor the changes in the construction site, many sensors are used, such as the Global Positioning System (GPS) [27], RFID [28], and ultrawideband (UWB) [29]. However, those sensors can only obtain the rough shape of obstacles but are difficult to acquire high-resolution $3 \mathrm{D}$ information of the environment. And, those onboard sensors can only observe some nearest dynamic change or obstacles; thus, the replanned path which is adjusted based on such local information may keep close to obstacles; this increases the collision possibility during the crane operation [30]. To fully identify the shape of obstacles and changes of environmental information in the construction site, many 3D measurement technologies are developed to build a comprehensive $3 \mathrm{D}$ model of the as-is construction site, such as the GIS and the laser-based sensors [31] and the camera-based sensors [8,32]. However, both the LiDAR and camera systems are required to be fixed on the construction site. As a result, when in the congested construction site, it is difficult for the two technologies to always maintain a clear line of sight under the influence of moving objects, which limits their information gathering effectiveness [33].

To address this challenge, mobile information capturing system is considered, such as the camera system on mobile unmanned aerial vehicles (UAVs) [34]. Based on the onboard cameras on the UAV, a series of hybrid images can be continuously collected during low-altitude flights; meantime, the GPS and camera pose information will be captured and stored for each image. Thus, the image position can be determined, based on which, contextual UAV images can be matched. Then, a 3D surface model can be modeled by photogrammetry methods quickly [33].

2.2.2. Crane Operation Path Planning. For decades, researchers have endeavored to improve both the efficiency and safety of crane operations. Considering the multipledegree-of-freedom (DoF) of cranes, robotic motion planning methods are adopted for reference to develop crane path planning algorithms [35]. Those algorithms are mainly divided into global path planning algorithms and local path planning algorithms. Generally, in the preconstruction phases, when fully designed information of modules and construction site layout is available, global path methods are adopted to find the optimized path for both single or multiple cranes. To incorporate the dynamic nature of the construction site, local path planning methods (or path replanning methods) were developed by repeatedly searching the neighborhood local information and analyzing until no better path could be found [36].

However, in the path planning tasks, enormous gathered environment information is required to be imported into an algorithm, which leads to heavy workloads. Besides, to reduce the computational cost, the environment information is always sampled by different representation methods (e.g., coordinate system model, network system model), which may lead to low resolution for collision detection [37]. Facing the above two mentioned challenges, BIM shows superior advantages to other technologies. On the one hand, the BIM is able to store and share a large amount of information and thus can realize automatic information input for path plan algorithms. On the other hand, it can be used to $4 \mathrm{D}$ simulate the process of lift planning by attaching the designed schedule information to the $3 \mathrm{D}$ visible models [16].

2.3. Brief Summary of the Related Researches. The above sections briefly introduced the application of BIM and UAV in the AEC industry and presented the typical issues involved in crane path determination. According to the review, the UAV is adopted to capture the geometric data of the construction site or to conduct the safety check together with BIM. However, few studies integrated the two applications of UAVs. In addition, few studies focused on the application of BIM and UAV in steel bridge construction with a modular construction method.

Therefore, this attempts to integrate BIM- and UAVbased models at the application level to provide an accurate way in crane path planning. BIM is adopted to create the crane and building model, and the images obtained by UAV are adopted to analyze the existing environmental information. Thus, by integrating the designed 3D model of BIM and the as-is environment model of UAV images, the crane path plan was $4 \mathrm{D}$ simulated. Also, the reliability of the designed lift operation could be detailed monitored dynamically. Furthermore, the as-is model can also be used for project schedule inspection and management.

Compared to the existing literature, the major contributions of this case study can be summarized as follows: (1) UAV equipment was used to capture spectral images, based on which the real as-is construction site was modeled by Structure from Motion (SfM) photogrammetry method. Then, a fusion method of multiple source data (triangulated irregular network and BIM) was practiced to obtain the $3 \mathrm{D}$ modeling needed for construction simulation. (2) More precise and collision-free mobile crane lift operation planning was achieved. Then, the lifting planning of the selected overpass civil bridge project was discussed. The application process and results can provide good references for overpass bridge construction management. (3) A UAV-based construction process inspection was briefly practiced in this study. 


\section{Project Description}

3.1. General Information on the Project. The high-level bridge in this study is a section of an urban expressway connecting the center zone and the harbor of Changshu City in Jiangsu Province, China. The bridge was designed as an overpass to avoid an intersection with an existing road. The length of the high-level bridge was $179.6 \mathrm{~m}$. The bridge superstructure composed of steel box girders was supported by four column piers. The appearance of the bridge is shown in Figure 1, and some detailed information is shown in Table 1.

\subsection{Environment Features and Construction Method. The} newly constructed expressway was designed to cross over an existing expressway with a steel bridge. Near the construction site, the existing expressway crosses the ground urban route by a concrete bridge. As part of the provincial expressway network, the existing expressway serves heavy cross-border traffic and urban vehicles every day, and the traffic on the urban route is also heavy. To minimize the influence of bridge construction on normal traffic, it is necessary to reduce construction noise, shorten the duration of on-site construction, and adopt safe construction methods.

To meet the above requirements, the superstructure of the bridge was modularized. The steel components were prefabricated, and the construction was assembly-oriented to shorten the on-site construction time. In addition, incremental launching construction technology was applied to the steel bridge construction. By pushing the superstructure to the designed position with jacks, this construction technology optimized the lifting location of the superstructure segments. Hence, the interruption of bridge module transportation on the existing expressway could be minimized during construction.

Furthermore, considering the independent construction procedures and limited construction sites, higher requirements of the construction process were needed for both construction skills and construction management. Firstly, the separate work of fabrication, transportation, and lifting of the segments requires great precision during construction. Secondly, the narrow construction site of the bridge, which is only about $44 \mathrm{~m}$ in width, limits the crane's lifting action. Therefore, the risk of collision between the crane and the nearby structures is higher than in traditional constructions. Therefore, the lift path should be carefully planned, and experienced workers are needed to ensure the safety and efficiency of the construction. The location and field situations before, during, and after construction are shown in Figure 2.

3.3. BIM and UAV-Based Methodology. In this research, BIM and UAV simulation technologies were used to improve construction safety and efficiency, and the process of the research is shown in Figure 3. A $3 \mathrm{D}$ model of the bridge project was first built by BIM software (Bentley Systems). Next, the UAV was used to survey the geological conditions of the construction site, and engineering feature analysis was applied to transforming the collected information into design parameters. Finally, the integration of the above models with relevant construction methods was completed. The final designed 3D BIM model with performance simulation data was generated, which was used to simulate and preview the construction sequence of the steel bridge. When construction problems such as the risk of crashes are identified through construction process simulation, the construction plan will be modified and resimulated until an appropriate construction plan is achieved. In addition, to ensure the quality and the progress of the bridge project, UAV is used during construction to gather real-time on-site 3D models of the bridge. This facilitates the planned construction process, and the actual process could be checked vividly. The detailed methodology involved in this study is shown in Figure 4.

\section{3D BIM Superstructure Modeling}

4.1. Superstructure Parameters. The superstructure was designed with straight plane lines, $8000 \mathrm{~m}$ radius convex circle curves, and quadratic parabolic per-cambers. Furthermore, as shown in Figure 5, the cross section of the superstructure is a combination of a single box and triple cells, with horizontal bottom plates, inclined side webs, and top plates with a $2 \%$ bidirectional cross slope. The top width, bottom width, and middle height of the cross section are $25 \mathrm{~m}, 16.4 \mathrm{~m}$, and $2.8 \mathrm{~m}$, respectively.

In order to facilitate the transportation and lifting of the superstructure, the steel box was divided into 10 longitudinal sections along with bridge direction, denoted as $\mathrm{A} \sim \mathrm{J}$, and each section was further divided into 8 horizontal sections, denoted as $1 \sim 8$. Therefore, the entire steel bridge was composed of a total of 80 precast parts, denoted as A1 to J8. The scheme can be seen in Figure 6.

The amount of modeling effort can be changed with the detail of the model. A Level of Detail (LOD) specification was developed by the American Institute of Architects (AIA) and further explained by the BIMForum to better describe the details of components. In this study, to ensure all the information required for construction simulation was included in the BIM model, a LOD 400 model was built to accurately define the type of materials, layouts, locations, heights, elevation profiles, specific geometries, and locations. The plane line, vertical curve, longitudinal slope, and divided plan of the steel structure were also defined.

4.2. Superstructure Modeling. In order to conduct the modeling work efficiently, BIM systems for the modeling were selected. In this study, the Bentley System was used because of its great advantages in basic civil engineering (roads, railways, bridges, municipalities, water conservancy, etc.) [38]. The BIM software packages used in this study are MicroStation and Power civil. The corresponding hardware facilities used in the research are shown in Table 2.

The uniqueness of steel box girder components means that they could not be modeled quickly based on the elements or templates included in the software. An appropriate modeling method is, therefore, determined to increase the 


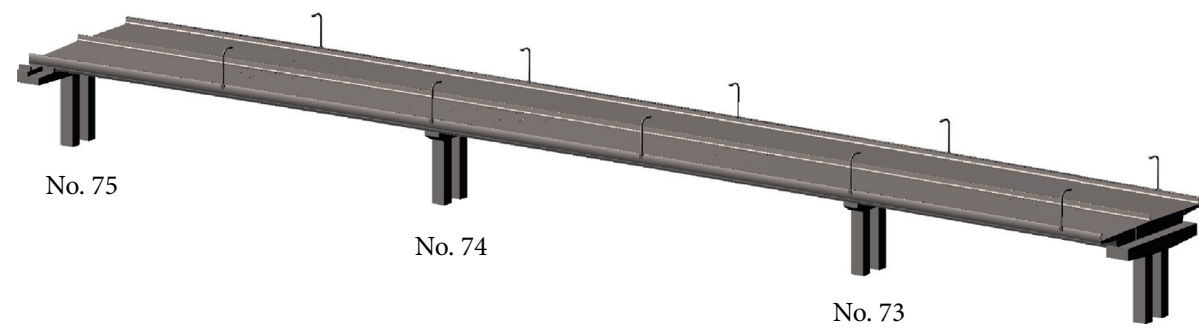

No. 72

FIgURE 1: Appearance of the steel bridge.

TABLE 1: Detailed information on the steel bridge.

Pier number Mileage station Span length Superstructure Overall length of the bridge Design speed

Cross section Design reference period
No. $72 \sim$ No. 75

$\mathrm{K} 13+374.783 \sim \mathrm{K} 13+444.783$

$47.3 \mathrm{~m}+70 \mathrm{~m}+62.3 \mathrm{~m}$

Steel box bridge with continuous girder

$179.6 \mathrm{~m}$

$80 \mathrm{~km} / \mathrm{h}$

$0.5 \mathrm{~m}$ (guard fence) $+11.75 \mathrm{~m}$ (lanes) $+0.5 \mathrm{~m}$ (median divide $)+11.75 \mathrm{~m}$ (lanes $)+0.5 \mathrm{~m}$ (guard fence $)=25 \mathrm{~m}$ 100 years
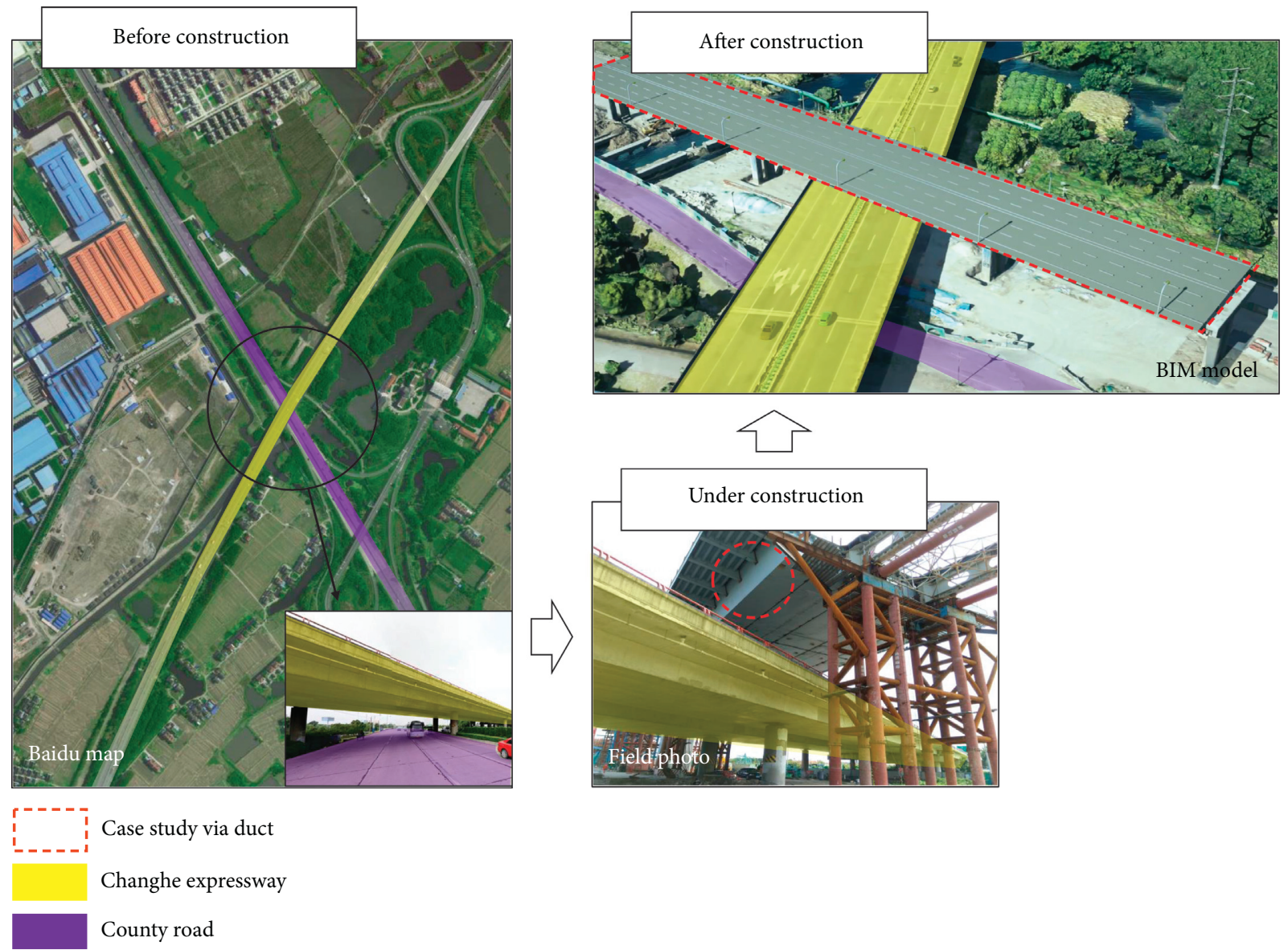

Figure 2: Location and field situation of research bridge (overpassing an existing high-level bridge). 


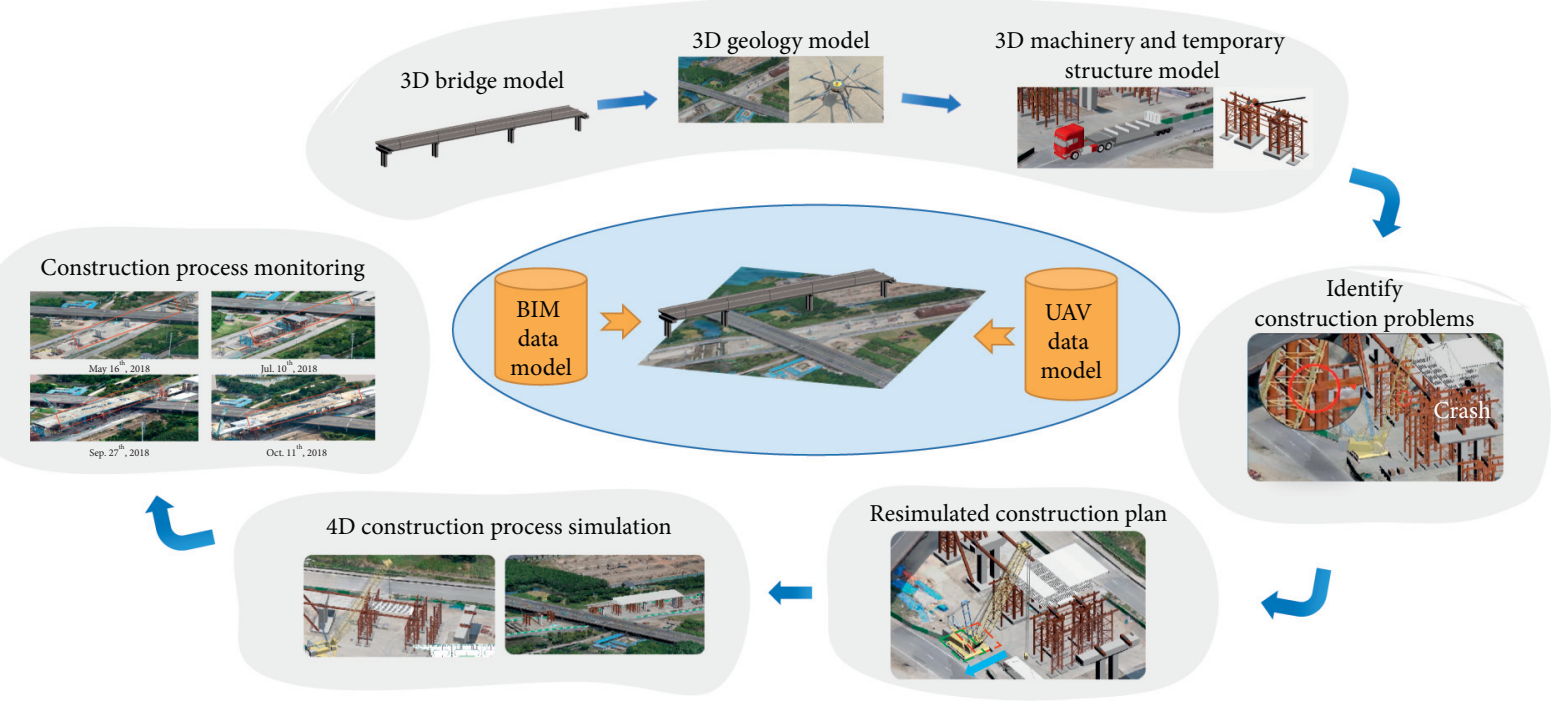

Figure 3: BIM and UAV coupled research process.

efficiency of the modeling process. Considering the different geometrical characters, the components of the steel structure can be divided into two categories. One type is the components of one categorical feature with the same cross section along the centerline, such as the webs. Another kind of component is often distributed along the longitudinal direction of the bridge at regular intervals in a single form, such as the crossbeams.

The designed 3D centerline of the superstructure was first modeled by Power civil, and the 3D centerline was combined with information on the designed plane line, vertical line, and precamber line. Then, two different modeling methods were conducted for the two categories of components. Open Bridge Modeler software was used to create the cross templates of the former kind of components. This kind of component was modeled by the lofting tool based on the cross section templates and the 3D centerline. For the second type, an element library was created using MicroStation, which covered all kinds of needed components, and then, the placement tool was used to complete the modeling work. After that, a complete superstructure model was gained by combining these elements and then divided into vertical splits and horizontal splits. The modeling process, which required about 160 hours' work by experienced BIM engineers, is shown in Figure 7. Then, the superstructure model was combined with the pier model to obtain the entire bridge model, as shown in Figure 8. Due to the page limit, the pier modeling method is not described in this paper.

\section{Position Acquisition of the Construction Site}

In this study, the UAV platform was used to model the $3 \mathrm{D}$ construction site surface. After UAV photogrammetric flights obtain a series of image sequences with a certain overlap rate for the target area, the features of the images were analyzed by Structure from Motion (SfM) photogrammetry. This photogrammetry technology is an image-based technology that can extract feature points from multiple overlapping $2 \mathrm{D}$ images and maps them into a 3D space. Then, after computing critical parameters (e.g., camera pose information), 3D coordinates of surface points can be obtained. In this way, accurate documentation of the construction site was achieved, and textured 3D models were quickly produced by the photogrammetric process [39]. Parameters of the UAV used in this research are shown in Table 3.

To build the 3D on-site model of the construction field, four major steps were conducted as follows:

(1) Scope of the construction site in the model: the construction site was about $200 \mathrm{~m}$ in length and about $44 \mathrm{~m}$ in width. An expressway crossed the top of the site. In order to better assist construction planning and reduce the influence of boundary deformation on the spatial data of the 3D model, the established ground model was larger than the project construction site, which was finally decided to be $1000 \mathrm{~m}$ in length and about $400 \mathrm{~m}$ in width

(2) Design of flight configuration: in order to facilitate 3D model reconstruction of the construction site, images were captured from different directions. A dual-strip UAV flight mode was designed: one strip parallel to the bridge direction and the other perpendicular to the bridge direction. The navigation parameters of the two routes are shown in Table 4

(3) Flight operations and data collection: flight operations were carried out on site from 11:00 am to 13:00 $\mathrm{pm}$. The drone performed a full-automatic flight and photographed according to preset strips to obtain digital photographs of the construction site. At the same time, the position information of each photo was automatically recorded, and the total data generated in this research was $50 \mathrm{~Gb}$ 


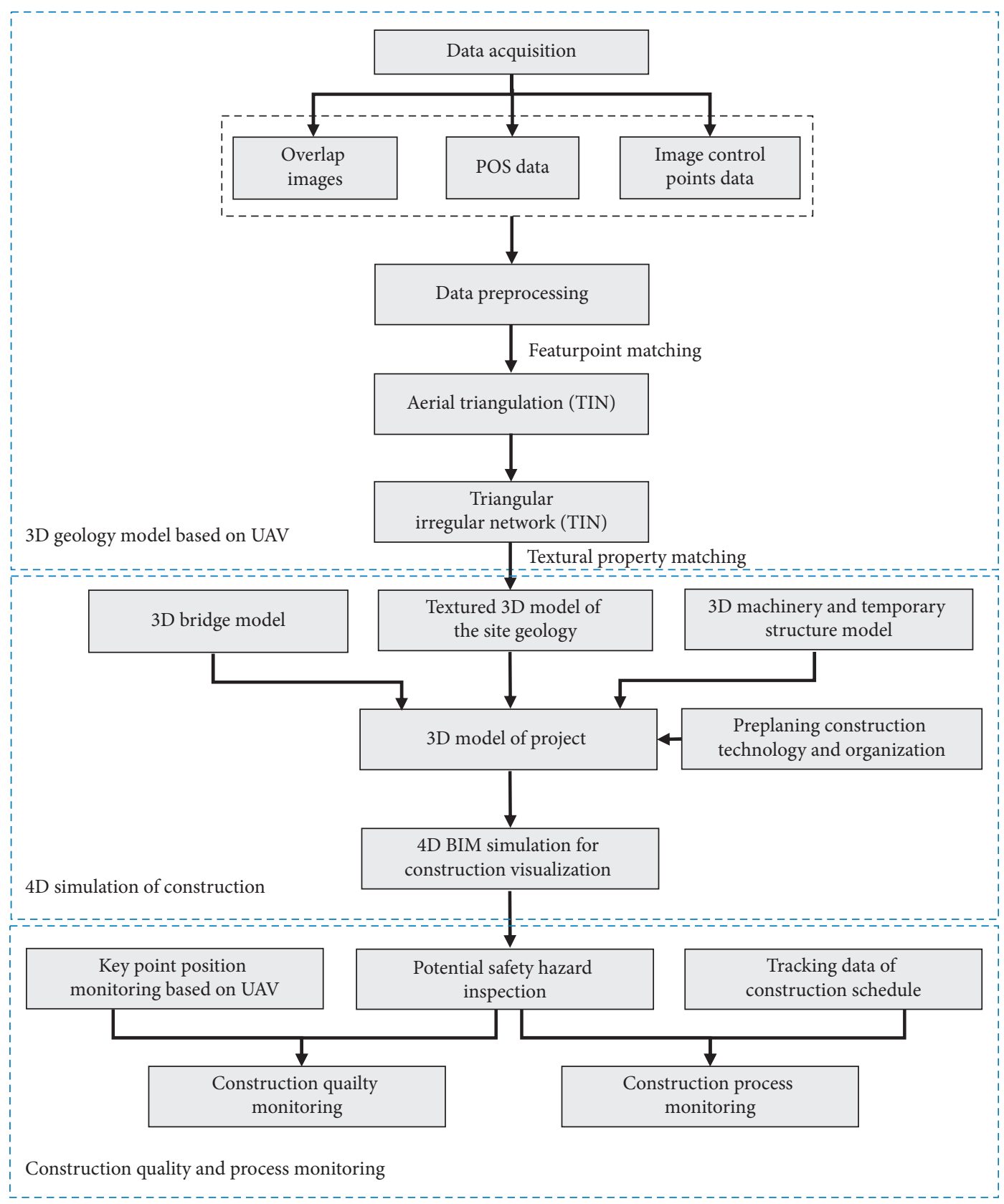

FIgUre 4: The detailed methodology of BIM and UAV.

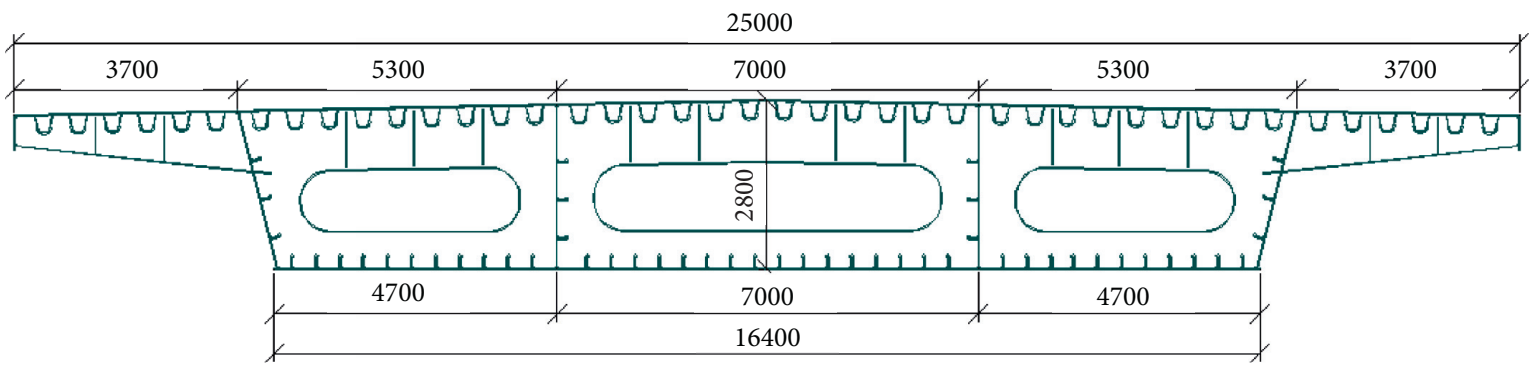

FIgURE 5: Cross-sectional view of the steel girder. 

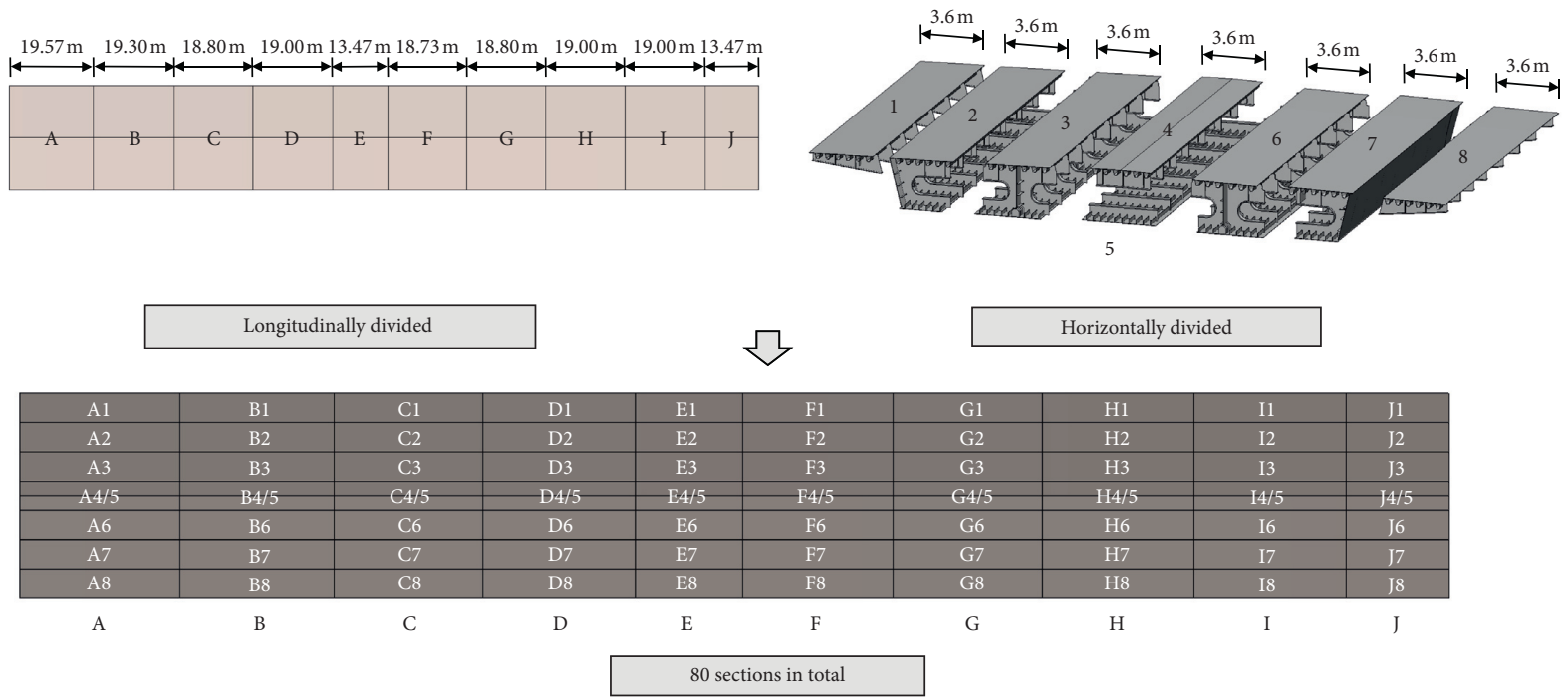

Figure 6: Components of the steel bridge.

TABLE 2: Hardware used in the study.

\section{CPU}

RAM

Graphics card

Motherboard

System i7-8700

$64 \mathrm{~g}$

NVIDIA 1080Ti 11G

AOC27

Windows ${ }^{\circledR} 10$

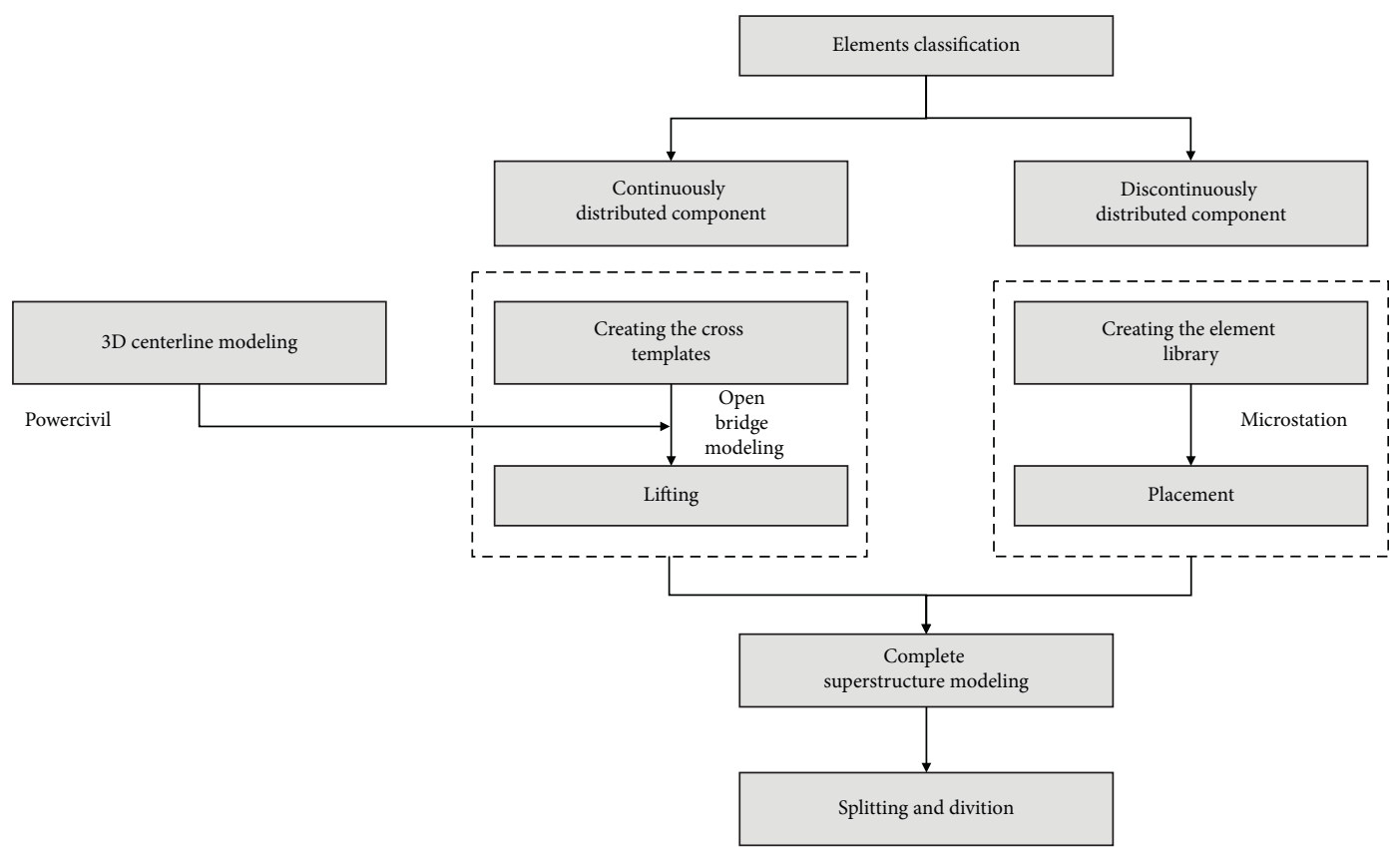

FigURE 7: Bridge superstructure modeling process. 


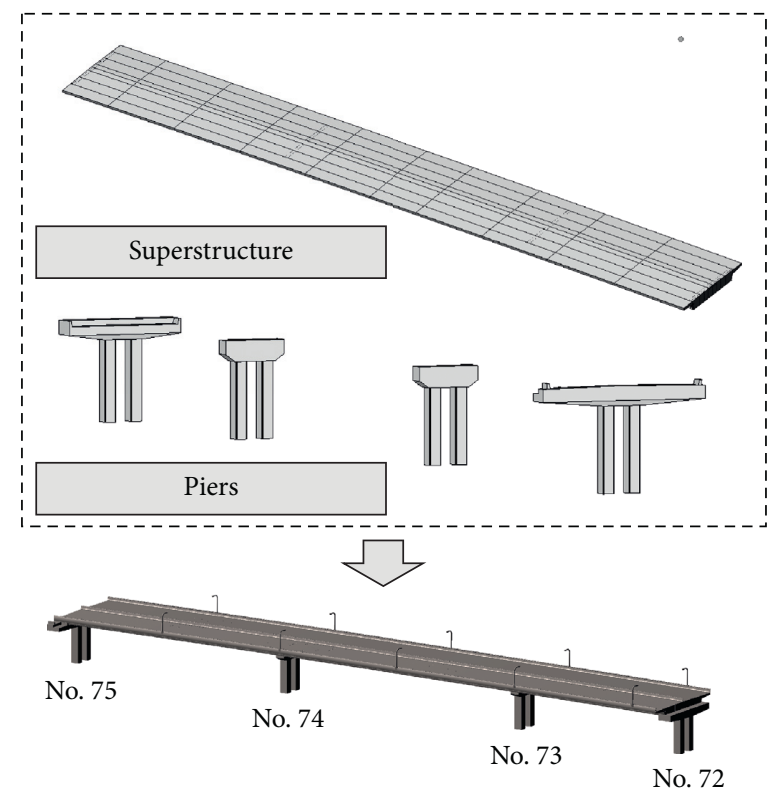

FIgURE 8: Entire bridge modeling process.

TABLe 3: Key specifications of UAV.

Model name

Number of axes

Wheelbase

Maximum flight speed

Maximum flight height

Maximum flight time

GPS positioning accuracy

Camera pixels

\section{ZR-60B \\ 6 \\ $1000 \mathrm{~mm}$ \\ $75 \mathrm{~km} / \mathrm{h}$ \\ $1000 \mathrm{~m}$ \\ $45 \mathrm{~min}$}

Horizontal accuracy: $\pm 1.5 \mathrm{~m}$
Vertical accuracy: $\pm 0.5 \mathrm{~m}$

TABLE 4: Navigation parameters of the two flying routes.

\begin{tabular}{lcc}
\hline Dual-strip flight modes & Perpendicular & Parallel \\
\hline Flight height & $220 \mathrm{~m}$ & $200 \mathrm{~m}$ \\
Side overlap & $60 \%$ & $80 \%$ \\
Heading overlap & $91 \%$ & $91 \%$ \\
Total flight distance & $8.5 \mathrm{~km}$ & $12.6 \mathrm{~km}$ \\
Total flight time & $18 \mathrm{~min}$ & $29 \mathrm{~min}$ \\
\hline
\end{tabular}

(4) 3D model construction: Context Capture software, which is software for $3 \mathrm{D}$ reconstruction by $\mathrm{SfM}$ algorithm, was used in this study for terrain reconstruction. After importing the data into Context Capture, a 3D digital surface model was generated after terrain reconstruction. The procedures of $3 \mathrm{D}$ digital surface modeling, including triangular meshing, shaded relief, and texture mapping, are presented in Figure 9.

Dense point cloud data were obtained from the reconstruction procedure. In the point cloud data, the construction site surface was made up of millions of $3 \mathrm{D}$ coordinate points, and the spatial geometric information was stored therein. The $3 \mathrm{D}$ coordinate calculation system of the point cloud data is the WGS84 geodetic coordinate system. Therefore, these point cloud information contained almost all external geometric features of the construction site. The virtual site surface reconstructed by the point cloud data was identified and extracted, as shown in Figure 10.

\section{Crane Operation Simulation and Working Path Planning}

For the project studied in this paper, the narrowness of the construction site may cause more difficulties in the crane plan. In the construction site, the construction materials and semifinished structures were stacked below and on one side of the bridge piers. Therefore, the crane could only be set up on the other side of the piers. In particular, the distance from the pier cover beam to the fence was only $19 \mathrm{~m}$, while the width of the previously selected crane was $7.68 \mathrm{~m}$, which limits the mobility of the crane. In addition, during the 


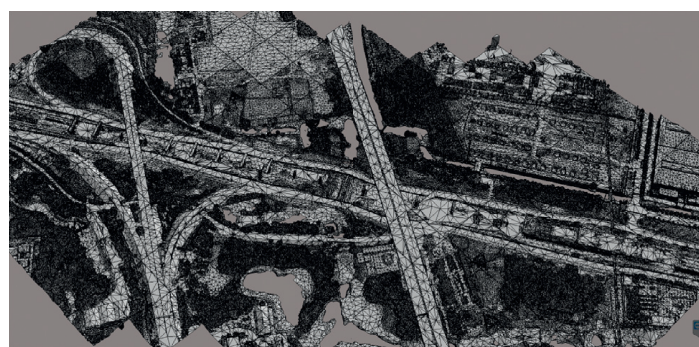

(a)

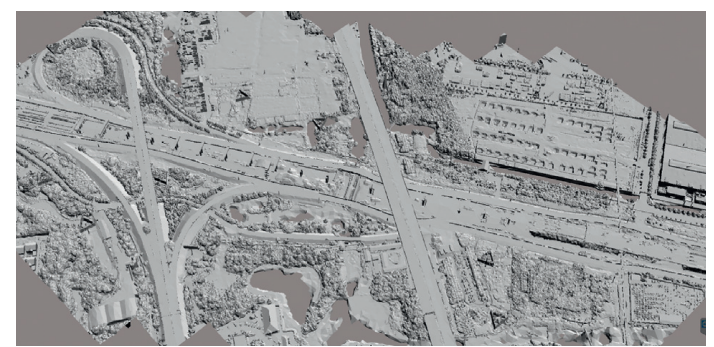

(b)

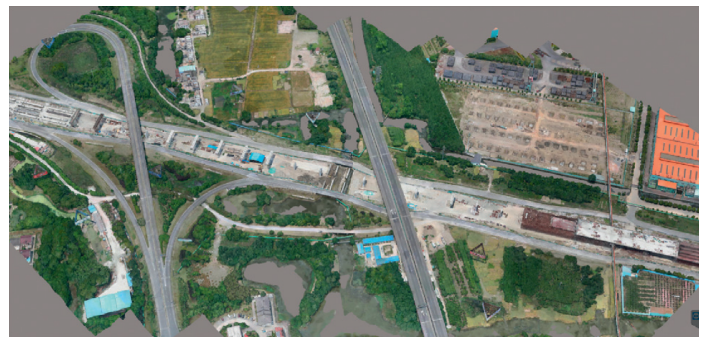

(c)

Figure 9: Reconstruction of the construction site by UAV, with three steps. (a) Triangular meshing. (b) Shaded relief. (c) Texture mapping.

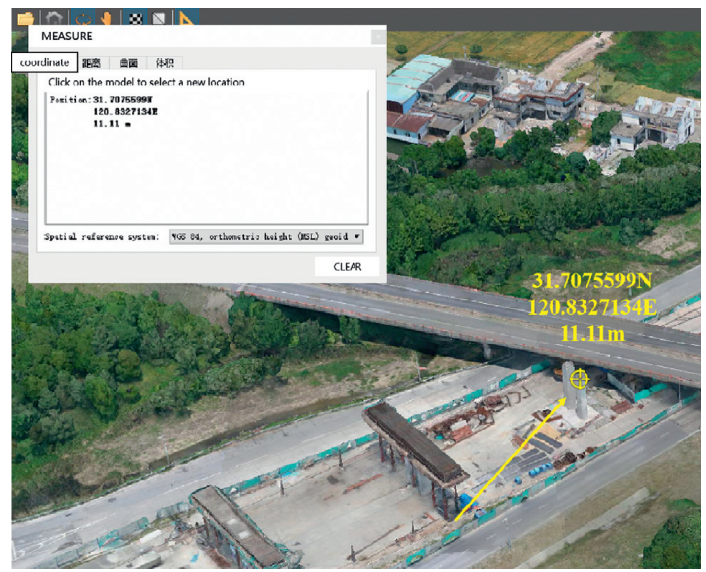

FIgURe 10: Position acquisition of construction site.

operation of cranes, conflicts may occur because of the complex interactions between the crane, structure modules, and the site layout. Thus, the piers and the temporary brackets could easily collide with the cranes during lifting, which may result in safety hazards. In order to verify potential risks in the construction plan, the combination of BIM and UAV, the selection of the crane, and the analysis of the crane workspace were studied, respectively.

6.1. Modeling of Temporary Facilities. The construction facilities, including temporary brackets and the bracings between piers and brackets, were modeled and then linked with the 3D site model in 3DMax to achieve an actual visualization of the construction environment, as shown in Figure 11.

The selected crane was also modeled by using 3DMax. The key dimensions considered for the modeling work included the sizes of the crane base and cabin, the mast height, jib length, as well as the locations, and the lifted superstructure sections. A 3D model of the crane was built, as shown in Figure 12.

Next, models of the track used to transport the steel structures and the jacks fixed to the piers and brackets were built. This provides the foundation for progress analysis after the integration of the above models using 3Dmax software.

6.2. Conflict Analysis between the Crane and Other Structures. The lifting task of the crane for each prefabricated component can be divided into three parts. First, the prefabricated segment is lifted upward until above the pier or bracket, then it is rotated to the specified installation position, and finally, the segment is lowered to complete the installation. Based on the prepared 3D model, the construction process of the crane was easily checked. The first step was to transition the as-planned schedule and construction methods, to crane-specific phases. After assigning 


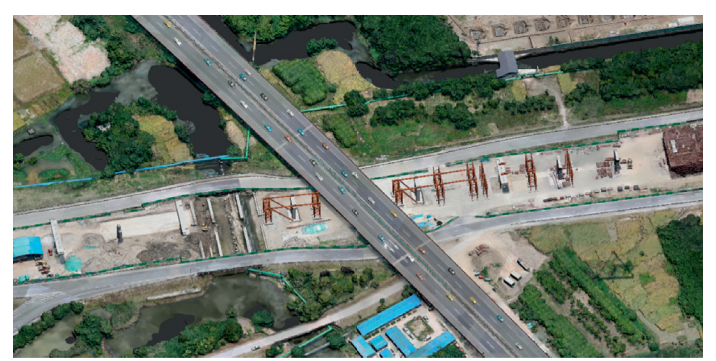

FIGURE 11: 3D visual construction of the site.

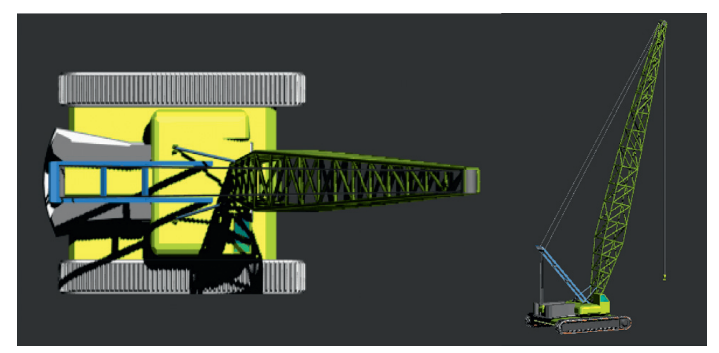

Figure 12: 3D crane model.

the as-planned schedule to the crane model as well as each of the objects in the as-is $3 \mathrm{D}$ construction site model, potential collisions could be detected. Because of the flexibility of the sling and the inertia of the motion, two methods were used in this study for detection. One was to discover the absolute collisions, which have to be eliminated by changing the initial construction plan. The other was to detect the risk of collision when the distance of the lifted load or crane and the nearby structures was within a threshold for safe clearance, which was set at $0.4 \mathrm{~m}$ in this research. Based on the conflict analysis in this research, a geometric conflict was identified between the crane and brackets during rotation, and two more potential conflicts were found within the safe clearance during rotation.

According to the conflict analysis results, to eliminate those potential conflicts, a new lifting plan was proposed by changing the jib length of the crane from $43.5 \mathrm{~m}$ to $46.5 \mathrm{~m}$, which enabled the prefabricated segment to be lifted higher, and helped to increase the distance of lifting loading and nearby structures when rotating. Therefore, a 3D model of the crane with $46.5 \mathrm{~m}$ jib length was prepared and connected with the as-planned schedule, and no conflicts were found after simulation.

6.3. Crane Working Path and Foundation Treatment Planning. Crane lifting planning usually includes two basic components: crane location decision and lifting path planning [40]. To minimize the working time and the moving time of the crane, an optimum route was proposed to achieve the most efficient combination of horizontal and vertical motions without potential conflicts. It was determined that there were 18 lifting points for the 80-beam sections, each lifting point was completed on average for $3 \sim 4$ modules, and the maximum is 8 modules. Consistent with the actual construction coordinates, the coordinate

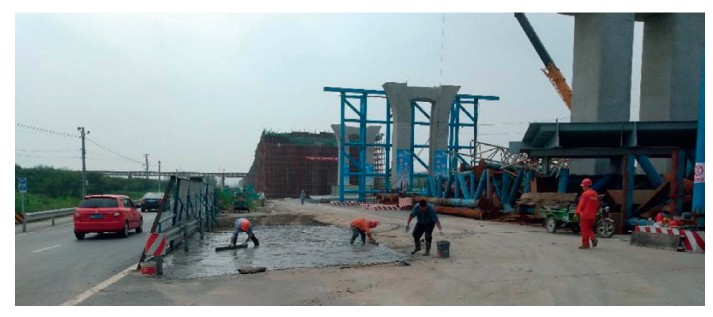

Figure 13: Ground enhancement for crane settlement.

information of the 3D as-is construction model was used to obtain the $3 \mathrm{D}$ coordinate information of the determined 18 lifting points; thus, a more precise lifting plan of the crane was achieved.

When lifting heavy loads, such as the A3 prefabricated section with a weight of 47.27 tons, considerable dynamic overturning is applied, which should be balanced by the counterforce provided by the foundation. Affected by the river near the construction site, the bearing capacities of some crane lifting areas were weak. Therefore, costly foundation treatment is needed to be carried out in advance. The optimized crane working path and 18 lifting positions made it possible to accurately determine the foundation treatment area. The area was $293 \mathrm{~m}^{2}$ according to the $3 \mathrm{D}$ digital surface model. Therefore, the lifting site was cleaned, leveled, and reinforced, as shown in Figure 13.

\section{Construction Progress Monitoring}

In a typical construction, time-related matters may be the most important issues. On-site inspection of the construction process is usually carried by the manager moving around the structure, which is time-consuming. Therefore, methods to monitor the construction progress during the construction process quickly and fairly are required. Imagebased progress tracking technology by UAV enables progress data to be collected quickly, accurately, and effectively. Compared with photographs and 3D scanning, UAV enables the cost-effective synchronous acquisition of image information and spatial information, making it suitable for construction management [41].

Therefore, after the analysis of the construction simulation, 4D (3D geometric information and schedule information) BIM technology was used to vividly present the above optimized as-plan construction process, and UAVbased aerial photogrammetry was conducted four times for process monitoring as well as site surveying.

7.1. 4D Construction Process. By linking the construction schedule with the $3 \mathrm{D}$ model, $4 \mathrm{D}$ technology was used to simulate the construction schedule of the superstructure. The workflow of lifting and launching was simulated in this research. As stated earlier, the superstructure was divided into ten longitudinal sections, each of which was divided into eight horizontal sections. The lifting sequence of the eight horizontal sections was identical, as shown in Figure 14. For each lifting operation, the location and the number of the lifting section, which are illustrated 


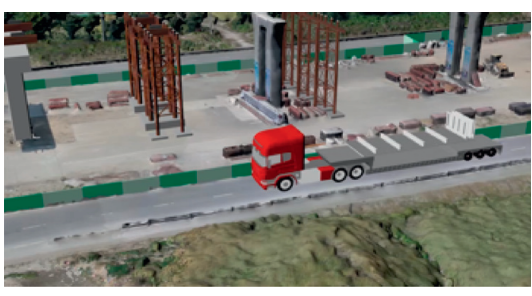

(a)

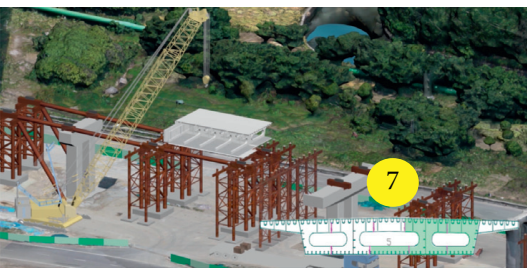

(d)

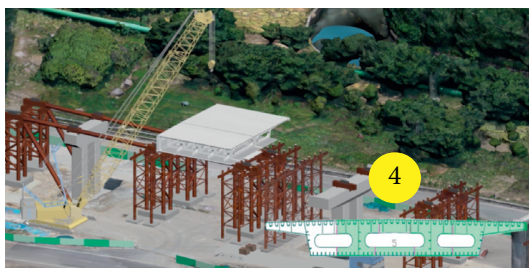

(g)

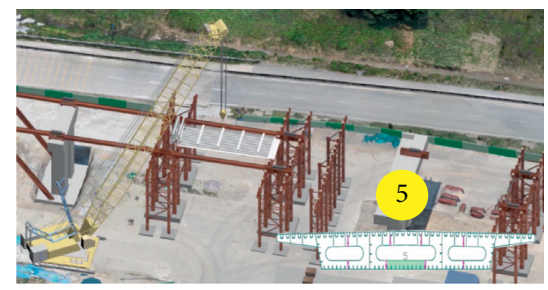

(b)

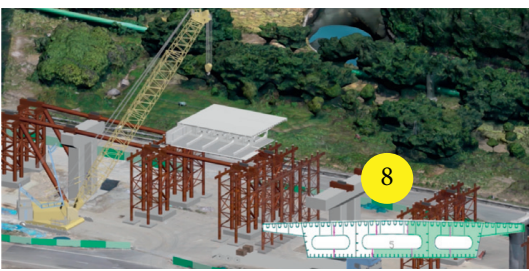

(e)

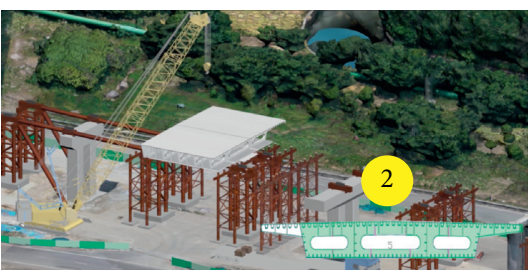

(h)

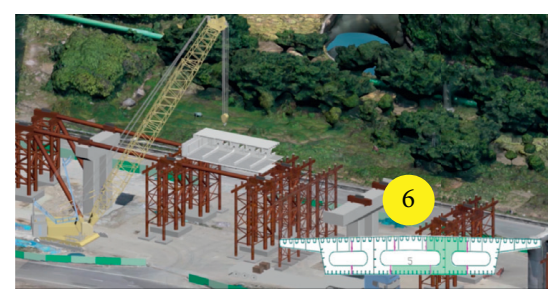

(c)

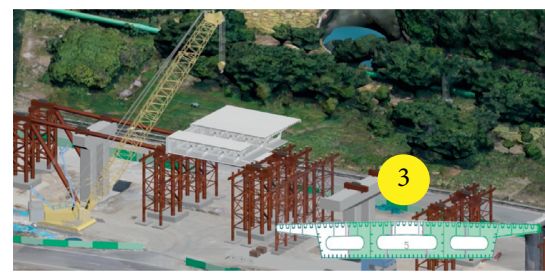

(f)

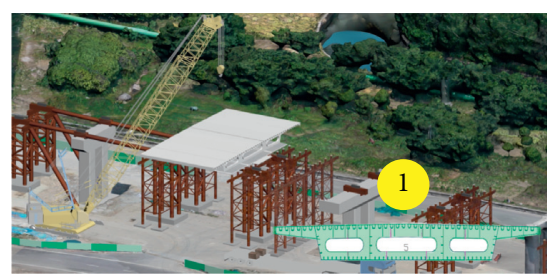

(i)

FIgURE 14: Simulated lifting process of horizontal sections. (a) Transporting J5 section. (b) Lifting J5 section. (c) Lifting J6 section. (d) Lifting J7 section. (e) Lifting J8 section. (f) Lifting J3 section. (g) Lifting J4 section. (h) Lifting J2 section. (i) Lifting J1 section.

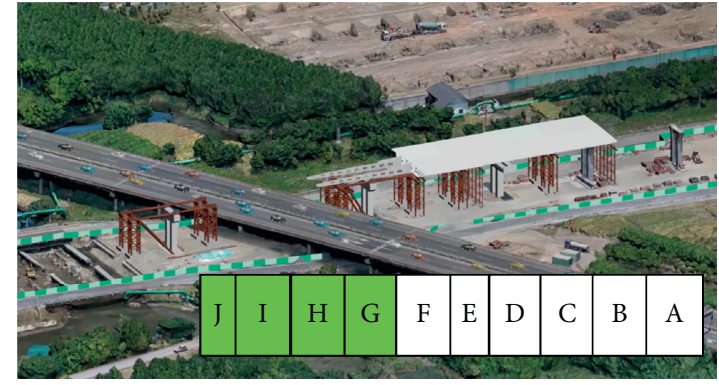

Lifting J, I, H, and G sections

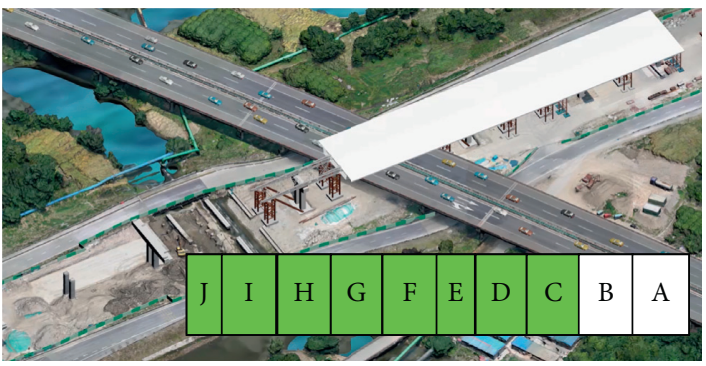

Lifting F, E, D, and C sections

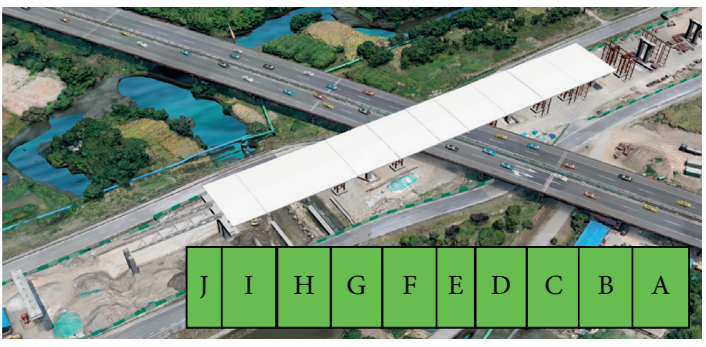

Lifting B and A sections

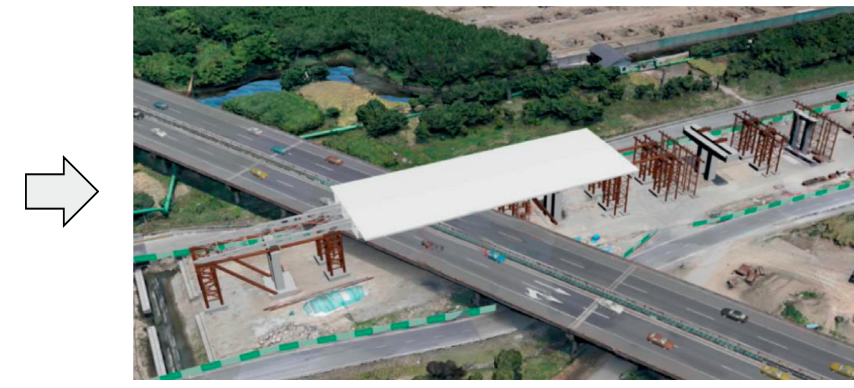

First pushing

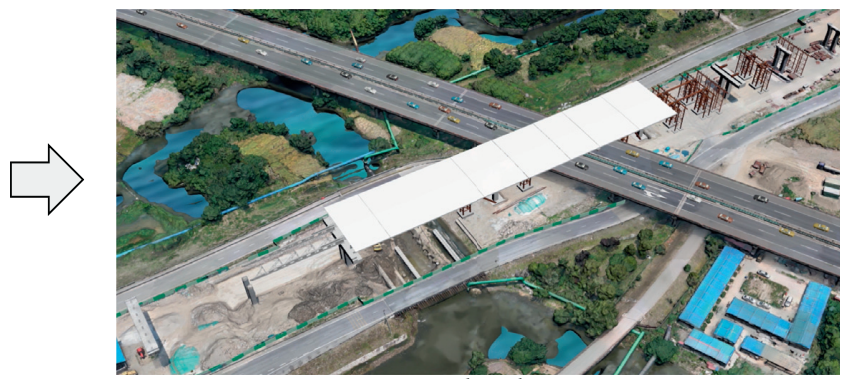

Second pushing

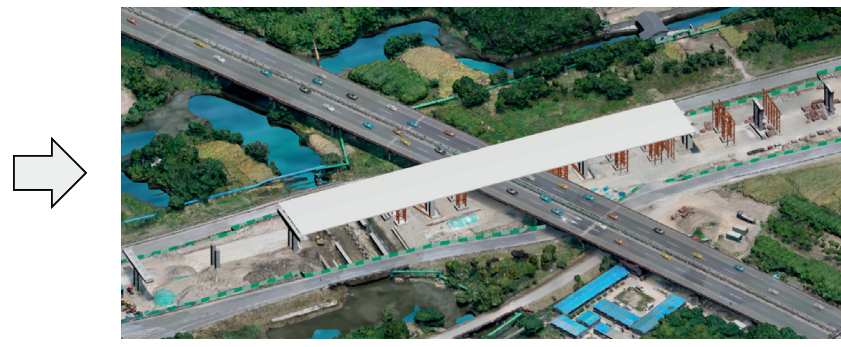

Falling of the superstructure

Figure 15: Simulation of lifting and pushing process. 


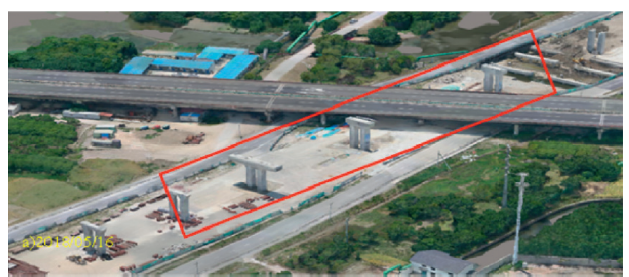

(a)

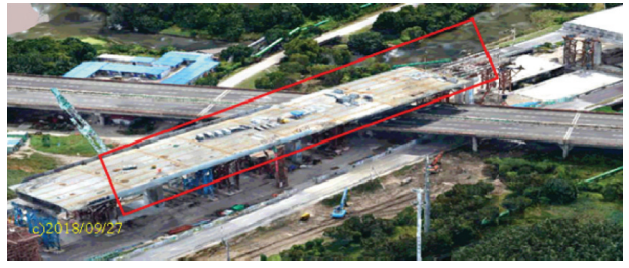

(c)

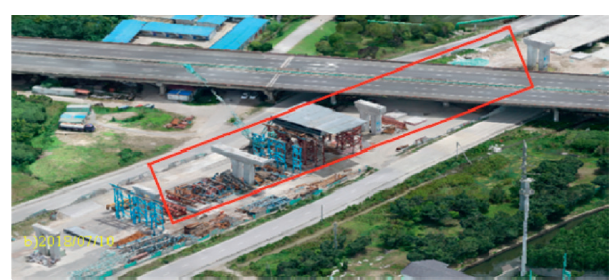

(b)

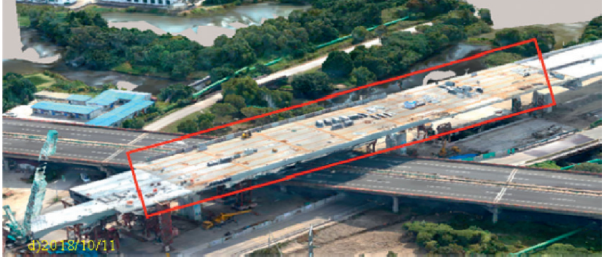

(d)

FiguRE 16: 3D models reconstructed from UAV for visualization and off-site monitoring. (a) May 16, 2018, (b) July 10, 2018, (c) Sep. 27, 2018, and (d) Oct. 11, 2018.

specifically in Figure 6, are shown in the bottom right corner of each picture. The lifting sequence of the longitudinal sections was divided into three parts, as shown in Figure 15. First, the J, I, H, and G segments and the guide beams were lifted. After the first pushing, the F, E, D, and C segments were lifted and the second push was carried out. Then, the $B$ and $\mathrm{A}$ sections were lifted, the guide beam was removed, and the superstructure was placed on the piers.

7.2. UAV Construction Monitoring. During different periods of project construction, photographs of the scene were collected by UAV to collect accurate spatial information and visualize the construction progress, as shown in Figure 16. The project manager compared the planned progress with the actual progress according to the time node and performed engineering measurements on the as-is model to carry out the initial inspection of the project's progress and can measure the constructed structure size to check the engineering quality.

\section{Practical Implications}

This study introduced the application of BIM and UAV in a steel bridge construction project. Specifically, based on the $\mathrm{BIM}$ and UAV, the potential safety risks were inspected before the construction, and the mobile crane location, as well as the jib length, was determined consequently. In addition, based on the virtual model, the operation path of the mobile crane was clarified, and therefore, the ground enhancement area was calculated. Finally, the UAV also provided real-time monitoring of the construction site and the schedule. This study shows that the integration of BIM and UAV has the potential to optimize the crane lifting plan and realize real-time construction monitoring. This study optimizes the traditional modular construction of a steel bridge and enhances construction safety. Furthermore, the methods adopted in this study are useful not only for the optimization of crane lifting planning but also for other construction management applications.

\section{Summary and Conclusions}

In this study, the BIM- and UAV-based models were integrated at the application level to provide more precise information for mobile crane path planning. An overpass bridge project with a congested construction site was selected as an example. The main conclusions are as follows:

(1) The camera system on a mobile UAV was used to obtain a series of hybrid images of the construction site. The images were then being matched by the SfM photogrammetry method to model the $3 \mathrm{D}$ as-is construction site. This method frees the acquisition of construction sites from the blocking of obstacles comparing with fixed cameras and can be further utilized in construction progress monitoring and control applications

(2) A fusion model, including the BIM lifting modules, the as-is construction site, and the crane model, was established to simulate the lifting process of the mobile crane. On this basis, the potential conflicts of the original crane operation path were detected before the construction, and the optimal lifting positions, as well as the optimized operation path, were then determined

(3) The fusion model was further combined with the schedule information to realizing a $4 \mathrm{D}$ simulation of the designed lifting plan, which enables the project manager to compare the actual construction progress to the schedule vividly

(4) Limited by the unavoidably UAV flight time costing and image match time costing, this method can realize nearly real-time construction site information updating and is promising for real-time information 
updating with the development of the data processing methods and computing technology

\section{Data Availability}

All data, models, and codes generated or used during this study appear in the published article.

\section{Disclosure}

The opinions, findings, and conclusions expressed in this publication are those of the authors and not necessarily those of any organization.

\section{Conflicts of Interest}

The authors declare that they have no conflicts of interest.

\section{Acknowledgments}

This work was undertaken with funding from the National Key Research and Development Project (no. 2019YFE0116300), the Transportation Science Research Project of Jiangsu Province (no. 2019Y69), sponsored by the "333" high-level talent training project in Jiangsu, and the Postgraduate Research and Practice Innovation Program of Jiangsu Province (no. KYCX20_0134).

\section{References}

[1] "2019 traffic analysis report of major cities in China," 2020, https://tech.sina.com.cn/roll/2020-02-28/doc-iimxyqvz6368353. shtml.

[2] N. Wang, Research on Transverse Separated Blocks Hoisting Construction of a Steel Box Girder Viaduct, Zhejiang University, Hangzhou, China, 2019.

[3] Announcement of the General Office of the Ministry of Housing and Urban-Rural Development on the Production Safety Accidents of Housing and Municipal Engineering in 2019, 2020, http://www.mohurd.gov.cn/ wjfb/202006/t20200624_246031.html.

[4] S. Zhang, J. Teizer, J.-K. Lee, C. M. Eastman, and M. Venugopal, "Building information modeling (BIM) and safety: automatic safety checking of construction models and schedules," Automation in Construction, vol. 29, pp. 183-195, 2013.

[5] S. Alizadehsalehi, A. Hadavi, and J. C. Huang, "BIM/MR-lean construction project delivery management system," in Proceedings of the 2019 IEEE Technology \& Engineering Management Conference (TEMSCON), pp. 1-6, IEEE, Atlanta, GA, USA, June 2019.

[6] K. Tantisevi and B. Akinci, "Automated generation of workspace requirements of mobile crane operations to support conflict detection," Automation in Construction, vol. 16, no. 3, pp. 262-276, 2007.

[7] K. Kim and M. Kim, "RFID-based location-sensing system for safety management," Personal and Ubiquitous Computing, vol. 16, no. 3, pp. 235-243, 2012.

[8] J. Chen, Y. Fang, and Y. K. Cho, "Real-time 3D crane workspace update using a hybrid visualization approach," Journal of Computing in Civil Engineering, vol. 31, no. 5, pp. 04017049.1-04017049.15, 2017.
[9] H. Freimuth and M. König, "Planning and executing construction inspections with unmanned aerial vehicles," Automation in Construction, vol. 96, pp. 540-553, 2018.

[10] S. Alizadehsalehi, I. Yitmen, T. Celik, and D. Arditi, "The effectiveness of an integrated BIM/UAV model in managing safety on construction sites," International Journal of Occupational Safety and Ergonomics, vol. 26, no. 4, pp. 829-844, 2020.

[11] S. Alizadehsalehi, A. Hadavi, and J. C. Huang, "From BIM to extended reality in AEC industry," Automation in Construction, vol. 116, Article ID 103254, 2020.

[12] A. Ibrahim and M. Golparvar-Fard, "4D BIM based optimal flight planning for construction monitoring applications using camera-equipped UAVs," in Proceedings of the ASCE International Conference on Computing in Civil Engineering 2019, pp. 217-224, Atlanta, GA, USA, June 2019.

[13] S. Lee and Y. Choi, "Reviews of unmanned aerial vehicle (drone) technology trends and its applications in the mining industry," Geosystem Engineering, vol. 19, no. 4, pp. 197-204, 2016.

[14] D. H. Kim, B. K. Lee, and S. Y. Sohn, "Quantifying technology-industry spillover effects based on patent citation network analysis of unmanned aerial vehicle (UAV)," Technological Forecasting and Social Change, vol. 105, pp. 140-157, 2016.

[15] S. Dorafshan and M. Maguire, "Bridge inspection: human performance, unmanned aerial systems and automation," Journal of Civil Structural Health Monitoring, vol. 8, no. 3, pp. 443-476, 2018.

[16] Y. Chen, J. Zhang, and B. C. Min, "Applications of BIM and UAV to construction safety," in Proceedings of the 7th International Construction Conference Jointly With the Construction Research Congress (CRC 2019), pp. 1-7, Montreal, Canada, June 2019.

[17] F. Xie, Z. Lin, D. Gui, and H. Lin, "Study on construction of 3D building based on UAV images," ISPRS International Archives of the Photogrammetry, Remote Sensing and Spatial Information Sciences, vol. XXXIX-B1, 2012.

[18] J. Irizarry and D. B. Costa, "Exploratory study of potential applications of unmanned aerial systems for construction management tasks," Journal of Management in Engineering, vol. 32, no. 3, Article ID 05016001, 2016.

[19] J. Wang, S. Zhang, and J. Teizer, "Geotechnical and safety protective equipment planning using range point cloud data and rule checking in building information modeling," $\mathrm{Au}$ tomation in Construction, vol. 49, pp. 250-261, 2015.

[20] M. Rashidi and B. Samali, "Health monitoring of bridges using RPAs," in Proceedings of the 16th East Asian-Pacific Conference on Structural Engineering and Construction, 2019, pp. 209-218, Springer, Brisbane, Australia, January 2021.

[21] P. Sharafi, M. Rashidi, B. Samali et al., "Identification of factors and decision analysis of the level of modularization in building construction," Journal of Architectural Engineering, vol. 24, no. 2, Article ID 04018010, 2018.

[22] L. Ramli, Z. Mohamed, A. M. Abdullahi, H. I. Jaafar, and I. M. Lazim, "Control strategies for crane systems: a comprehensive review," Mechanical Systems and Signal Processing, vol. 95, pp. 1-23, 2017.

[23] H. Shin and J. Chae, "A performance review of collision-free path planning algorithms," Journal of Electronics, vol. 9, no. 2, p. 316, 2020.

[24] M. R. Endsley, "Situation awareness misconceptions and misunderstandings," Journal of Cognitive Engineering \& Decision Making, vol. 9, no. 1, pp. 4-32, 2015. 
[25] G. Baoyi, Z. Xianzhang, and H. Yongjiang, "Review of visual object tracking technology," Journal of Image and Graphics, vol. 23, no. 8, pp. 1091-1107, 2018.

[26] Z. Zhang and W. Pan, "Lift planning and optimization in construction: a thirty-year review," Automation in Construction, vol. 118, Article ID 103271, 2020.

[27] H. Wu, Y. Yin, S. Wang et al., "Optimizing GPS-guidance transit route for cable crane collision avoidance using artificial immune algorithm," GPS Solutions, vol. 21, pp. 823-834, 2017.

[28] X. J. Zheng, J. B. Zeng, and H. Zhang, "Research of intelligent monitoring system of tower crane based on RFID," Advanced Materials Research, vol. 706-708, no. 1, pp. 990-994, 2013.

[29] S. Hwang, "Ultra-wide band technology experiments for realtime prevention of tower crane collisions," Automation in Construction, vol. 22, pp. 545-553, 2012.

[30] G. Chen, D. Liu, Y. Wang et al., "Path planning method with obstacle avoidance for manipulators in dynamic environment," International Journal of Advanced Robotic Systems, vol. 15 , no. 6 , pp. 1-18, 2018.

[31] T. Cheng and J. Teizer, "Modeling tower crane operator visibility to minimize the risk of limited situational awareness," Journal of Computing in Civil Engineering, vol. 28, no. 3, pp. 04014004.1-04014004.15, 2012.

[32] J. Yang, P. Vela, J. Teizer et al., "Vision-based tower crane tracking for understanding construction activity," Journal of Computing in Civil Engineering, vol. 28, no. 1, pp. 103-112, 2014.

[33] Y. Fang, J. Chen, and Y. K. Cho, “A point cloud-vision hybrid approach for 3D location tracking of mobile construction assets," in Proceedings of the 33rd International Symposium on Automation and Robotics in Construction (ISARC 2016), Auburn, AL, USA, July 2016.

[34] K. Nakano, H. Suzuki, T. Tamino et al., "On fundamental evaluation using UAV imagery and 3D modeling software," ISPRS-International Archives of the Photogrammetry, Remote Sensing and Spatial Information Sciences, vol. XLI-B5, pp. 93-97, 2016.

[35] M. Hoy, A. S. Matveev, and A. V. Savkin, "Algorithms for collision-free navigation of mobile robots in complex cluttered environments: a survey," Robotica, vol. 33, no. 3, pp. 463-497, 2015.

[36] C. Zhang and A. Hammad, "Improving lifting motion planning and re-planning of cranes with consideration for safety and efficiency," Advanced Engineering Informatics, vol. 26, no. 2, pp. 396-410, 2012.

[37] Y. Sining, Y. Shaowu, and Y. Xiaodong, "An efficient spatial representation for path planning of ground robots in $3 \mathrm{D}$ environments," IEEE Access, vol. 6, pp. 41539-41550, 2018.

[38] M. W. Li, W. C. Hong, J. Geng et al., "Berth and quay crane coordinated scheduling using multi-objective chaos cloud particle swarm optimization algorithm," Neural Computing \& Applications, vol. 28, pp. 3163-3182, 2017.

[39] P. Chen, Y. Huang, P. Eleonora, J. Mou, and P. Van Gelder, "Global path planning for autonomous ship: a hybrid approach of fast marching square and velocity obstacles methods," Ocean Engineering, vol. 214, 2020.

[40] Y. Fang, Y. K. Cho, and J. Chen, "A framework for real-time pro-active safety assistance for mobile crane lifting operations," Automation in Construction, vol. 72 , no. 3, pp. 367-379, 2016.
[41] S. H. Lee, S. H. Woo, J. R. Ryu, and S. Y. Choo, "Automated building occupancy authorization using BIM and UAV-based spatial information: photogrammetric reverse engineering," Journal of Asian Architecture and Building Engineering, vol. 18, no. 2, pp. 151-158, 2019. 